Check for updates

1 Association of Schools of Public Health in the European Region

2 Public Health Unit, Health Sciences Institute, Catholic University of Portugal

Cite this as: $B M J 2021 ; 375: \mathrm{n} 3157$ http://dx.doi.org/10.1136/bmj.n3157

Published: 29 December 2021

\section{With covid-19, single measures aren't enough}

\author{
Single magic bullets for covid-19 do not exist, say John Middleton and Henrique Lopes
}

\author{
John Middleton, ${ }^{1}$ Henrique Lopes ${ }^{2}$
}

Recently, the director general of the World Health Organization, Tedros Adhanom Ghebreyesus, said "vaccines alone will not get any country out of this crisis. Countries can-and must-prevent the spread of omicron with measures that work today. It's not vaccines instead of masks. It's not vaccines instead of distancing. It's not vaccines instead of ventilation or hand hygiene. Do it all. Do it consistently. Do it well." As the pandemic progresses, we are understanding the weaknesses of each of the interventions we have in the armoury to combat covid-19. Some countries, including England, have put all their eggs in the vaccination basket and neglected other measures that need to be implemented at the same time.

Vaccination is still the best hope we have for reducing the virus to very low levels and preventing deaths and disability from the disease, but it is not the only answer. Social mixing without masking enables the virus to find new, unprotected, and vulnerable people to infect and harm. Every time the virus finds a new host, there is the potential for new, more vaccine resistant variants to form-as we have seen with the omicron variant.

The Swiss Cheese model has been used to show the need to employ all the pandemic control measures available, so that where one fails, another does the job. ${ }^{1}$ But this mentality and policy stance has not been conveyed by our political leaders.

Since the omicron variant was first identified, there have been some knee-jerk comments about it being "no more serious than a flu pandemic" or even "the same as the common cold." We now have preliminary data from two studies to suggest that omicron is less likely to lead to hospital admission of double vaccinated young adults compared with delta. However, the data also suggest that omicron is more transmissible; consequently, even if it is milder than previous variants, it may still lead to high numbers of hospital admissions due to the higher transmissibility rate. ${ }^{2}$

The greater transmissibility of omicron is already creating pressure through increased staff sickness absence in health services. Protecting health services is vital if services are ever going to be able to recover non-covid disease management and reduce their record waiting lists. As Chris Whitty, chief medical officer for England, observed before Christmas, it is an inversion of reality to think you can treat other high priority conditions when your hospital beds and intensive care units are filled with covid patients. We must be concerned about the undertreatment of chronic conditions and cancers, as well as the mental health impacts of stricter societal measures. Yet there is no capacity to manage these unless the pandemic is dealt with.

Norway, Denmark, Switzerland, and the UK are still in the grip of an exponential growth of covid infections, with omicron taking over as the prominent variant of concern. Czechia, Germany, Poland, Slovakia, Belgium, and Hungary have passed recent peaks of what is presumed to be the delta variant. Infection rates are rising in France, Sweden, Israel, Italy, Portugal, and Spain, but from a lower base. ${ }^{3}$ In Portugal, omicron is expected to make up $80 \%$ of cases in the New Year, despite the population having very high levels of vaccination coverage. Norway has imposed its strictest restrictions since the beginning of the pandemic in response to the escalation of cases. This includes a ban on alcohol sales in bars and restaurants. Households are limited to 10 people and public gatherings less than 50. Denmark has also responded with stricter measures, including the closure of public venues.

Late or incomplete interventions risk further damaging economies, with the main victims being those with the fewest resources who are also most at risk from covid-19. The recent advice from Chris Whitty that people should judge their priorities for what social events they go to echoed the conclusion many people had already reached, but it nevertheless attracted further ill conceived criticism. It also highlighted how the failure of politicians to act meant that individuals were left to make decisions themselves, which left the hospitality industry vulnerable. These are societal choices that require politicians to stand up and make decisions. Throughout the pandemic, governments have second guessed what measures their electorates will agree to, frequently getting it wrong and being behind on what the public thinks is needed. ${ }^{4}$ Governments have often complied with vocal minorities, often fired up by symbolic and ideological positions rather than what the science says we should do.

A coherent strategy must also employ progressive social policies and legal and fiscal measures to protect people's income, employment, education, housing, security, and access to other necessary health and social care during the pandemic. It will also need to secure sustainable improvements in the working conditions for those who are most vulnerable and at risk from infection. This approach will provide a platform for better health, with populations more resilient to the worst effects of the pandemic. It would also limit worsening health inequalities and improve the performance of economies.

Finally, we need to restate that this virus will not be controlled or defeated unless we have global responses that are inclusive of all nations-north and 
south, rich and poor. ${ }^{5}$ Colonial attitudes to global vaccine production damage everyone. ${ }^{6}$ We need a vaccine TRIPS waiver now. It is to the shame of all governments that this is not happening, and the UK government's most recent pronouncement does not give any confidence that there is really a global effort to combat the pandemic. South Africa was severely "punished" by rich countries from the moment it announced the new variant of concern. What is the incentive for other countries to identify new variants and alert the world in future?

Our approach to the pandemic must be an integrated whole. We need to build trust and understanding in all our communities. People and politicians need to understand that single magic bullets for covid-19 do not exist.

Competing interests: JM is honorary professor of public health, Wolverhampton University. None further declared.

Provenance and peer review: not commissioned, not peer reviewed.

$1 \quad$ BBC News. Vaccines alone will not stop covid spreading. July 2021. https://www.bbc.co.uk/news/resources/idt-40ac92b1-1750-4e86-9936-2cda6b0acb3f

2 Christie B. Covid-19: Early studies give hope omicron is milder than other variants. BMJ 2021;375:n3144. doi: 10.1136/bmj.n3144. pmid: 34949600

3 Johns Hopkins University. Covid-19 data explorer. https://ourworldindata.org/explorers/coronavirus-data-explorer?zoomToSelection=true\&time=2020-03-01.latest\&facet=none\&pickerSort=asc\&pickerMetric=location\&Metric=Confirmed+cases\&Interval=7-day+rolling+average\&Relative+to+Population=true\&Align+outbreaks=false\&country=GBR DNK NOR CHE

4 Reicher S. It is wrong to claim that the public won't follow covid rules just because the government don’t. BMJ 2021;375:n3150. doi: 10.1136/bmj.n3150. pmid: 34952834

5 Rae M. Omicron: a failure to act with a global focus will continue the proliferation of new variants of covid-19. BMJ2021;375:n3095. doi: 10.1136/bmj.n3095. pmid: 34916212

6 Hassan F, London L, Gonsalves G. Unequal global vaccine coverage is at the heart of the current covid-19 crisis. BMJ 2021;375:n3074. doi: 10.1136/bmj.n3074. pmid: 34903557 